\title{
MONITORIA: DESAFIOS E PERSPECTIVAS NO IFS - CAMPUS LAGARTO
}

\author{
Bruno dos Santos Costa; Rosana Rocha Siqueira; Tiffany Brunelly Fontes Sacramento \\ Instituto Federal de Educação, Ciência e Tecnologia de Sergipe \\ brunosantos9182@gmail.com; hosanalilas393@yahoo.com.br; tiffanybfs@outlook.com \\ 10.15628/rbept.2017.5950 \\ Artigo submetido em maio/2017 e aceito em set/2017
}

\section{RESUMO}

O presente trabalho objetiva refletir sobre os desafios e perspectivas no âmbito do Programa de monitoria do Instituto Federal de Educação, Ciência e Tecnologia de Sergipe (IFS) no Campus Lagarto. Trata-se de um estudo exploratório qualitativo e quantitativo, cujo instrumento de coleta de dados (questionário) foi aplicado a discentes e docentes no período de novembro de 2016 a março de 2017. Após a análise dos dados pode-se observar que são muitos os desafios relacionados ao Programa de Monitoria, dentre eles o exercício contínuo, dialogado e colaborativo entre o docente-tutor e o discente-monitor, considerando a necessidade de acompanhamento dos discentes assistidos pela monitoria, o que exige preparação extra por parte do monitor que além de ampliar seu entendimento sobre a disciplina objeto da monitoria, precisa desenvolver habilidades comunicacionais e de relacionamento interpessoal. Pode-se observar que o programa de monitoria apresenta percepção positiva dos participantes envolvidos, destacando que para a ampliação das ações faz-se necessária à participação dos discentes de forma contínua, e não apenas na proximidade da realização de provas e atividades avaliativas.

Palavras-Chaves: monitoria, educação, ensino profissional.

\section{ABSTRACT}

The present work aims to reflect on challenges and perspectives within the Monitorship Program of the Federal Institute of Education, Science and Technology of Sergipe (IFS) Lagarto Campus. This is a qualitative and quantitative exploratory study, in which an instrument of data collection (questionnaire) was applied to students and teachers from November 2016 to March 2017. After analyzing the data, it can be observed that there are many challenges related to the Monitorship Program. Among them: the talked, collaborative and continuous practice between the teacher-tutor and the student-monitor, considering the students' needs for assistance from the Monitorship Program, which demands extra preparation by the monitor who, besides broadening his understanding of the discipline object of the monitorship, needs to develop communication and interpersonal skills. It can be observed that the Monitorship Program presents a positive perception of the participants involved. Worth mentioning that, in order to expand its actions, it is necessary the participation of the students in a continuous way and not only when exams and evaluation activities are imminent.

Keywords: monitorship, education, vocational education.violence. 


\section{Introdução}

A motivação para o estudo surgiu da observação do dia a dia dos discentes e docentes envolvidos no programa de monitoria do IFS - Campus Lagarto. Parte de esforços da gestão em proporcionar momentos de ensino-aprendizagem diferenciados, considerando os desafios dos discentes-monitores, dos docentes-tutores em oferecer oportunidade de aprofundamento e vivência além da carga horária em sala de aula.

A monitoria pode reunir uma gama de oportunidades em que todos os participantes podem ampliar seus conhecimentos e práticas didáticas, esclarecer dúvidas, revisar atividades que demandam mais tempo além da aula e principalmente exercitar o diálogo entre turmas diferentes estabelecendo relações importantes de mediação.

Neste contexto a monitoria na visão de Candau,

É entendida como instrumento para a melhoria do ensino, através do estabelecimento de novas práticas e experiências pedagógicas que visem fortalecer a articulação entre teoria e prática e a integração curricular em seus diferentes aspectos, e tem a finalidade de promover a cooperação mútua entre discente e docente e a vivência com o professor e como as suas atividades técnico-didáticas.

A monitoria, como procedimento pedagógico, tem demonstrado sua utilidade, à medida que atende às dimensões "política, técnica, e humana da prática pedagógica (CANDAU, 1986, p. 12-22).

Como discutido por Cunha Jr. (2009, p.10) a monitoria também pode ser encarada como uma nova divisão de trabalho proposta para aprendizagem escolar, onde os discentes monitores desempenham funções similares à dos docentes.

Os programas de monitoria podem ter objetivos variados, visando inserir discentes e docentes de diversas modalidades e níveis de ensino. Em nível médio pode ser entendida como uma oportunidade de reforçar os conteúdos explanados em sala de aula, como forma de construir e compartilhar conhecimentos, além de enriquecer o currículo do discentemonitor.

Neste contexto, o presente estudo elegeu o programa de monitoria do IFS - Campus Lagarto/SE, que reúne tanto discentes do curso médio integrado, quanto discentes em nível superior.

O referido campus localiza-se na cidade de Lagarto, na Região Centro-Sul do Estado de Sergipe. Siqueira, Vargas e Soares (2016, p.81) explicam que o Campus foi inaugurado em fevereiro de 1995, como UNED (Unidade Descentralizada de Ensino) ainda no contexto nacional dos Centros Federais de Educação Tecnológica - CEFET), que a partir do ano de 2008 foram redimensionados como IFs (Institutos Federais de Educação, Ciência e Tecnologia).

A instituição tem destaque na cidade de Lagarto e adjacências por oferecer variadas modalidades de ensino técnico e tecnológico, representando oportunidades de desenvolvimento e ascensão profissional para centenas de estudantes matriculados.

Possui cerca de 1020 discentes distribuídos nos cursos de: Bacharelado em Física e Sistemas de Informação (BSI); Tecnólogo em Automação industrial; Ensino Médio Integrado em Edificações, Eletromecânica, Informática e Redes; Técnico subsequente em Edificações, Eletromecânica, Informática e Ensino à Distância. 
De acordo com o Edital 2016/1 de seleção de monitores da instituição a monitoria é entendida como:

[...] instrumento para melhoria do ensino técnico e de graduação, por meio do estabelecimento de novas práticas e experiências pedagógicas que visem fortalecer a articulação entre teoria e prática e a integração curricular mútua entre estudantes e professores e, a vivência com o professor e com as suas atividades técnico-didáticas (EDITAL GEN/GAI/IFS 2016/1).

A base legal para o processo de monitoria encontra-se no Regulamento de Organização Didática (ROD) aprovado pela Resolução n.35/2016/CS/IFS de 28 de março de 2016. Neste bojo, o Programa de Monitoria de Ensino possui os seguintes objetivos:

I- Estimular a participação de estudantes dos cursos técnicos e de graduação no processo educacional, nas atividades relativas ao ensino e na vida acadêmica do IFS;

II- Favorecer o oferecimento de atividades de reforço escolar ao estudante com a finalidade de superar problemas de repetência escolar, evasão e falta de motivação;

III- Criar condições para a iniciação da prática da docência, através de atividades de natureza pedagógica, desenvolvendo habilidades e competências próprias desta atividade;

IV- Propor formas de acompanhamento de estudantes em suas dificuldades de aprendizagem;

$V$ - Pesquisar novas metodologias de ensino adequadas ao ensino da disciplina participante do programa;

VI- Contribuir através da formação e monitores de ensino, com a formação de recursos humanos para o ensino técnico e superior;

VII- Estimular a participação em projetos de pesquisa e extensão, no âmbito da disciplina.

Tais objetivos estão em consonância com Fidalgo e Fidalgo (2010, p. 29) na qual a educação profissional está centrada em novos paradigmas que dialogam com o mundo do trabalho, pois como sinalizado pelos autores, a educação tem sido fortalecida como uma ferramenta capaz de guiar à formação dos indivíduos que já compõem ou que ainda serão integrados pela "nova" sociedade, ainda em formação. Um tipo de sociedade que demandaria e revalorizaria o desenvolvimento de uma cultura geral, na qual ensinar e aprender seriam processos que acompanhariam cada indivíduo durante a vida; que tornaria a escola e a empresa mais próximas; que transformaria as relações de trabalho e que interferiria mais rigorosamente na objetividade e subjetividade do seu sujeito-labutador.

Observa-se que o docente-tutor tem um papel preponderante neste processo, visto que a ele é demandada a prática docente e pedagógica que irá orientar dentro de suas limitações considerando os objetivos do programa de monitoria.

A prática docente é prática pedagógica quando se insere na intencionalidade prevista para sua ação. Assim, enfatizo que um professor que sabe qual é o sentido de sua aula para a formação 
desse aluno, que sabe como sua aula integra e expande a formação desse aluno, que tem consciência do significado da própria ação, esse professor dialoga com a necessidade do aluno, insiste na sua aprendizagem, acompanha seu interesse faz questão de produzir aqueles aprendizado, pois acredita que este será importante para aluno [...] é prática que se exerce com finalidade, planejamento, acompanhamento, vigilância crítica, responsabilidade social (FRANCO, 2012, p. 160).

Cabe destacar que os objetivos da monitoria para o ensino médio profissionalizante diferem do disposto na Lei $n^{\circ}$ 5.540, de 28 de novembro de 1968 que fixa normas de organização e funcionamento do ensino superior e sua articulação com a escola média, e dá outras providências. A lei indica no artigo 41, que:

As universidades deverão criar as funções de monitor para alunos do curso de graduação que se submeterem a provas específicas, nas quais demonstrem capacidade de desempenho em atividades técnico-didáticas de determinada disciplina.

A monitoria no ensino superior dentre outros objetivos, busca inserir o discente em um primeiro contato com a iniciação à docência, reforçando aspectos dos processos de ensino e aprendizagem. Vários teóricos contribuíram para a ampliação do pensamento pedagógico relacionando teorias às novas metodologias para o ensino e aprendizagem, visto que "ensinar não é transferir conhecimento, mas criar as possibilidades para a sua produção ou a sua construção", (FREIRE, 1996, p. 21). Contudo os programas de monitoria voltados para o ensino médio possuem enfoque diferenciado, pois não objetivam a iniciação à docência, mas não deixam de contribuir para formação e autonomia do aluno como sinalizam Basso (1994) e Asbahr (2005).

[...] a formação crítica do aluno, possibilitando que este tenha acesso também ao processo de produção do conhecimento [...] Assim o aluno não é só objeto da atividade do professor, mas é principalmente sujeito e constitui-se como tal na atividade de ensino/aprendizagem na medida em que participa ativamente e intencionalmente do processo de apropriação do saber, superando o modo espontâneo e cotidiano do conhecer (ASBAHR, 2005, p.61).

Em especial para os monitores de cursos superiores Dantas (2014, p. 569), lembra que as variadas atividades que ocorrem com base na relação teoria e prática necessitam serem pautadas em trabalhos acadêmicos estimuladores de múltiplos saberes inerentes aos componentes curriculares, corroborando assim para a formação crítica durante a graduação e a pós-graduação, ao passo que fomenta no discente, o interesse pela docência na educação de nível superior.

O exposto acima foi notado, por exemplo, na monitoria das disciplinas de Cálculo IA e Cálculo IB (Figura 1), onde os monitores se prestam a tirar dúvidas de outros discentes por meio de exercícios teóricos baseados na temática estudada. Ao sanar inquietações referentes às temáticas abordadas em sala de aula, os monitores contribuem diretamente na elevação do conhecimento dos outros alunos, podendo isso inclusive fomentar o gosto pela docência. 


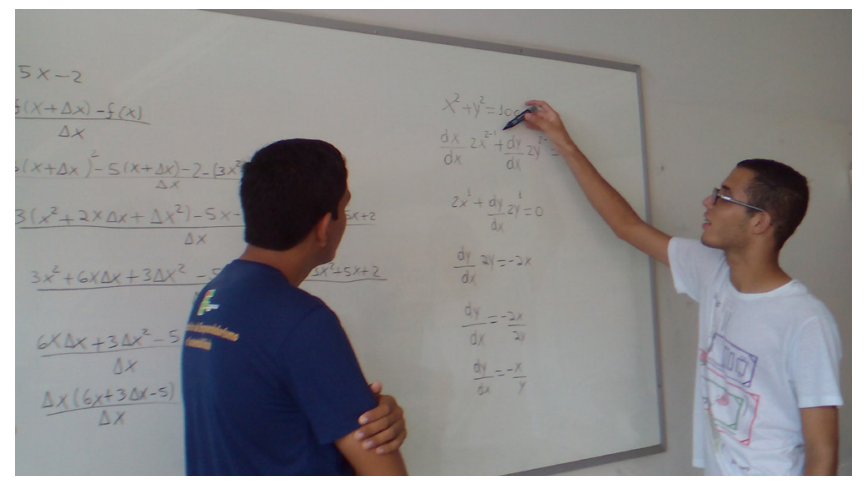

Figura 1. Esclarecimento de dúvidas na disciplina de Cálculo I. Autores, 2017.

Em nível de pós-graduação a monitoria também permite incluir a iniciação à docência. Friedlander (1984, p. 113) comenta o monitor é o discente que, possui interesse em ampliar seus conhecimentos em uma determinada disciplina e/ou área de conhecimento e junto a ela realiza pequenas tarefas ou trabalhos que favorecem o ensino, a pesquisa ou o serviço de extensão à comunidade dessa disciplina.

Nos Institutos Federais os programas de monitoria elencam o perfil que consideram adequados para o aporte de cada disciplina, desta forma tanto o professor tutor quanto a gestão escolar podem delinear as habilidades exigidas e as competências que serão desenvolvidas durante o processo de monitoria. Por exemplo, para a disputa da vaga de monitor na disciplina de Mecânica dos Solos, foi exigido um sólido conhecimento de Normas Brasileiras referentes a ensaios como: preparação de amostras, granulometria, plasticidade e consistência dos solos. Além de paciência com os alunos assistidos pelo programa, e obediência dos horários estipulados para a prática da atividade de monitoria, como pode ser observado na Figura 2 em que uma aluna-monitora assiste outra discente.

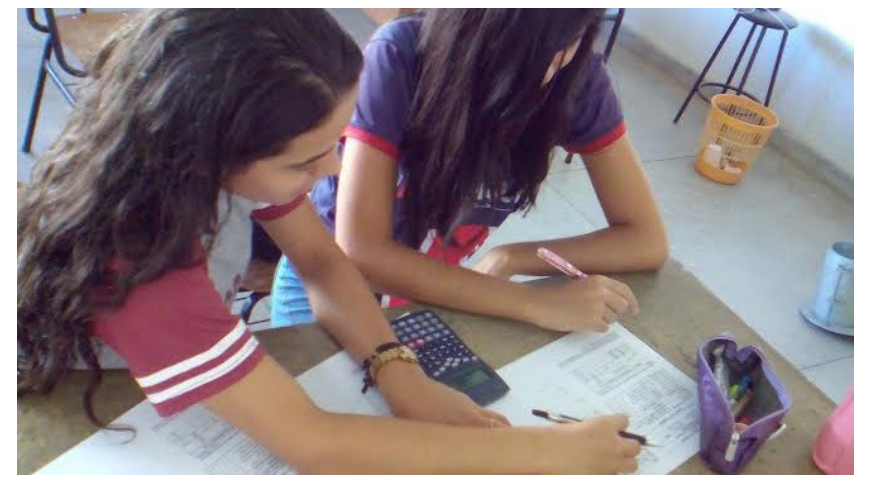

Figura 2. Esclarecimento de dúvidas na disciplina de Mecânica dos solos. Autores, 2017.

Como pré-requisitos básicos foram citados: matrícula regular e aprovação com êxito na disciplina na qual pleiteia a vaga para monitoria. Depois de selecionado o discente monitor faz jus a uma bolsa com valor entre $\mathrm{R} \$ 150,00$ ou $\mathrm{R} \$ 200,00$. Vale ressaltar que é vedado ao monitor o exercício da docência, bem como o assentamento de frequências, notas e demais atividades do cargo docente.

Na trajetória deste estudo várias questões vieram à tona em relação à vivência de professores, discentes monitores e discentes assistidos: o professor indica o perfil desejado ou a instituição é que indica? Em algum momento há dissonâncias entre a relação entre professor e monitor? Quais os maiores desafios enfrentados pelos monitores em suas rotinas? A partir destes questionamentos foi possível delinear o percurso metodológico desta pesquisa. 


\section{Metodologia}

Trata-se de uma pesquisa exploratória pautada em dados de campo coletados no IFS - Campus Lagarto/SE no período entre novembro de 2016 e março de 2017.

O universo foi composto por 19 monitores, 33 discentes assistidos no período e 16 professores de disciplinas cuja gestão identificou a necessidade de monitoria. As amostras aleatórias foram compostas por 07 discentes-monitores, 33 discentes assistidos e 06 professores tutores. Ressalta-se que o número de alunos assistidos pela monitoria é oscilante, considerando que este número pode variar uma vez que os monitores atendem à demandas irregulares, não há periodicidade no atendimento, este ocorre quando os alunos possuem dúvidas ou precisam de algum auxílio em práticas. Desta forma as disciplinas atendidas são:

\begin{tabular}{c|c}
\hline Ensino médio integrado & Ensino Superior \\
\hline Química I & Cálculo IA \\
\hline Química II & Cálculo IB \\
\hline Matemática I & Mecânica II \\
\hline Física I & Eletricidade \\
\hline Mecânica dos solos & Linguagem de programação II \\
\hline Desenho assistido por \\
computador
\end{tabular}

Tabela 1: Disciplinas atendidas pelo Programa de Monitoria IFS - Campus Lagarto 2016/1.

Fonte: Autores, 2017.

Em relação aos instrumentos de coleta de dados, foram aplicados questionários diferenciados com perguntas abertas para discentes assistidos pela monitoria, discentesmonitores e professores tutores.

Após a coleta de dados foi possível analisar as respostas objetivando a reflexão acerca dos desafios, pontos positivos e negativos do Programa de Monitoria do IFS - Campus Lagarto.

\section{Resultados e Discussões}

Diante do exposto nota-se que o programa de monitoria nem sempre parte da solicitação dos docentes, mas pode surgir devido ao alto grau de reprovação de uma disciplina, ou mesmo da solicitação dos discentes que necessitam de estudo dirigido.

Desta forma $60 \%$ dos docentes entrevistados afirmaram não ter solicitado o apoio de monitores, mesmo que atualmente contem com este auxílio. A maioria dos docentes (80\%) não precisaram de apoio pedagógico para traçar o perfil dos monitores, pois já tinham em mente as necessidades das disciplinas que seriam atendidas. Um professor destacou que no edital que norteou o processo havia alguns critérios de seleção que os discentes precisavam seguir para concorrer à oportunidade da monitoria após a realização de uma prova.

Um aspecto pareceu interessante, visto que além dos critérios do edital, todos os docentes citaram qualidades e habilidades desejáveis para um monitor, dentre elas: ser atencioso, prestativo, ter boas notas, gostar de compartilhar conhecimentos, ser dedicado, ter domínio do conteúdo, linguagem acessível aos alunos, ser positivo, responsável, ter envolvimento direto na problemática dos alunos entre outros aspectos. 
Alguns fatores importantes foram levados em consideração principalmente nas disciplinas que incluem práticas (Figura 3), operação de aparelhos, vidrarias, máquinas, estufas ou algum objeto que ofereça risco, neste sentido reforça-se a necessidade de o monitor possuir uma atenção aguçada.

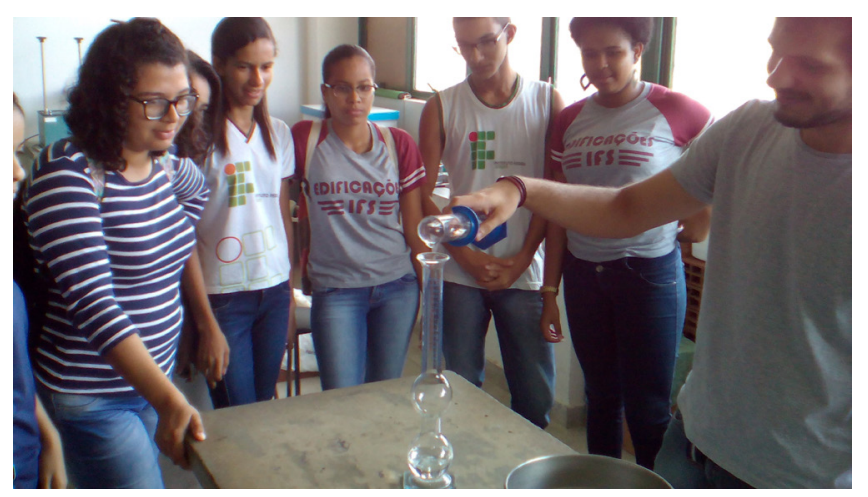

Figura 3. Ensaio de densidade absoluta sendo executado por monitor.

Autores, 2017.

Dentre os desafios citados pelos docentes estão a dificuldade de adequar os horários considerando que o ensino médio possui aulas quase todos os dias nos turnos manhã e tarde, necessidade de maior participação por parte da procura pela monitoria, e "ter bom convívio, visto que é preciso que todos tenham um envolvimento para que possam alcançar o mesmo objetivo: aprendizado" (Discurso do profo. 04).

Vale destacar que os processos de interação e de mediação na relação entre: "professor-aluno", "professor tutor - aluno monitor" e "aluno monitor e aluno assistido" aduzem a diferentes ações, considerando que segundo Tardif (2014) a ação de um docente é a ação de quem:

- Possui uma ideia, uma representação geral do objetivo que quer atingir;

- Possui um conhecimento adquirido e concreto sobre o material com o qual trabalha;

- Age baseando-se na tradição e em receitas de efeito comprovado [práticas];

- Age afiando-se também em sua habilidade pessoal e finalmente, age guiando-se por suas experiências, fonte de bons hábitos (IBDEM, 2014, p. 159).

As mediações e práticas entre o profissional docente e seu aluno são ancoradas em sua formação e em sua experiência cotidiana. 0 docente adequa o conhecimento e metodologias às necessidades dos alunos de acordo com a matriz curricular. 0 professor tutor orienta também o aluno monitor nas ações previstas no programa de monitoria e desta forma proporciona novas inter-relações no processo ensino aprendizagem.

Os discursos de dois docentes revelaram opiniões importantes:

"Para ser um monitor não é preciso apenas querer, é preciso engajarse e se comprometer com o que está fazendo" (Discurso do Profo. 02);

"Alguns alunos acham que objetivo da monitoria não seria alcançado, uma vez que a explicação do conteúdo pelo monitor pode e deve ser diferente da explicação do professor" (Discurso do Profo. 03). 
No âmbito dos discentes-monitores foram vários os motivos que geraram a vontade de participar do Programa de Monitoria, dentre eles a busca por mais experiência, o dinheiro da bolsa, o fator de gostar da disciplina, a oportunidade de desenvolver a comunicação e revisar os conteúdos. A maioria citou ter facilidade em lidar com pessoas, embora $20 \%$ tenham afirmado sentir insegurança e medo diante dos alunos a serem assistidos, medo e não ser capaz de auxiliar os discentes.

A facilidade da maior parte dos monitores do IFS - Campus Lagarto em lidar com pessoas é positiva no contexto da análise de Cunha Jr. (2009, p. 10), quando este cita que "os alunos têm autonomia para criar regras para a organização das relações no grupo, de acordo com as necessidades verificadas no contexto específico, não se preocupando apenas com avaliação ou comportamento que tradicionalmente organizam a sala de aula $[\ldots]^{\prime \prime}$.

Quanto à avaliação do Programa de monitoria, todos consideraram positiva a experiência, a saber, o comentário de uma participante: "Avalio como positiva, pois o convívio em grupo e a troca de conhecimento é de suma importância para o progresso de aprendizagem" (Discurso do Profo. 01).

Infere-se que os participantes desta pesquisa consideraram a monitoria como positiva, pois,

Este instrumento educacional "[...] propicia mais um espaço para o aluno discutir suas dúvidas, fazer ou refazer exercícios, experimentos e assim ter sua aprendizagem mediada pelo monitor, que, por sua vez, terá espaço de ação junto ao professor, podendo receber novos textos, experimentos e realizar discussões, alicerçando, dessa forma, seus conhecimentos e construindo novas sínteses relevantes para o desempenho de suas funções e formação acadêmica" (NATÁRIO e SANTOS, 2010, p. 357).

Os participantes indicaram também não ter presenciado problemas de atritos entre discentes e monitores e que os mesmos não possuem privilégios por conta da monitoria.

Ao serem questionados se gostariam de serem futuros monitores, a maioria indicou não ter o perfil para esta atividade. Não foi percebido grau de dissonância entre as respostas dos discentes do ensino superior e do ensino médio, tanto em relação aos discentes assistidos quantos aos monitores.

\section{Conclusão}

Nota-se que o Programa de Monitoria do IFS - Campus Lagarto apresenta-se como exitoso na percepção dos participantes, visto que docentes e discentes aprovam a inciativa.

Um dos pontos elencados por ambos foi a necessidade de maior procura por parte dos discentes assistidos, visto que a periodicidade é importante para continuidade dos estudos. Por vezes os discentes procuram auxílio na ocasião das provas ou de trabalhos o que pode "fragmentar" o processo de aprendizado.

Para alguns discentes-monitores, esta oportunidade proporcionou ampliação de conhecimentos ao desenvolver novas habilidades, firmando maior vínculo de interesse com a disciplina objeto da monitoria. Salienta-se que a possibilidade de troca de conhecimento com os orientadores (tutores) e discentes assistidos, denota uma grande forma de aprendizado. 
Por fim, entende-se que ao cooperar no processo de formação dos discentes, os monitores adquirem experiências positivas também para seu aprendizado.

\section{Referências Bibliográficas}

1. BASSO, I. S. As condições subjetivas e objetivas do trabalho docente: um estudo a partir do ensino de História. 1994. 123p. Tese (doutorado). Faculdade de Educação da Universidade Estadual de Campinas. Campinas, 1994.

2. ASBAHR, F. da S. F. (2005). Sentido pessoal e projeto político pedagógico: Análise da atividade pedagógica a partir da psicologia histórico-cultural. Dissertação de Mestrado, Universidade de São Paulo, São Paulo.

3. BRASIL, Instituto Federal de Educação, Ciência e Tecnologia de Sergipe. Resolução n.35/2016/CS/IFS de 28 de março de 2016.

4. Lei ${ }^{\circ}$ 5.540, de 28 de novembro de 1968. Disponível em: <http://www2.camara. leg.br/legin/fed/lei/1960-1969/lei-5540-28-novembro-1968-359201-publicacaooriginal-1-pl.html>. Acesso em 15 de mai. 2017.

5. $\quad$ CANDAU, V. M. F. A didática em questão e a formação de educadores-exaltação à negação: a busca da relevância. In: CANDAU, V. M. F. (org), A didática em questão. Petrópolis: Vozes, 1986, p. 12-22.

6. CUNHA Jr, F.R. Monitoria: uma possibilidade de transformação no ensinoaprendizagem no ensino médio. 2009. 133 f. Dissertação (Mestrado em Linguística Aplicada e Estudos da Linguagem), Pontifícia Universidade Católica de São Paulo, São Paulo, 2009.

7. DANTAS, O. M. Monitoria: fonte de saberes à docência superior. Revista Brasileira de Estudos Pedagógicos, Brasília, v. 95, n. 241, p. 567-589, set./dez. 2014. Disponível em: <http://dx.doi. org/10.1590/S2176-6681/301611386>. Acesso em: 14 de mai. 2017.

8. FIDALGO, Nara L. R.; FIDALGO, Fernando. Refluxos sociais da lógica de competências: o processo de individualização em foco. In.: Educação profissional e a lógica das competências. FIDALGO, Nara L. R et al. (org.). 2. ed. Petrópolis, RJ: Vozes, 2010, 204p.

9. $\quad$ FRANCO, Maria A. do Rosário Santoro. Pedagogia e prática docente. 1. ed. São Paulo: Cortez, 2012.

10. FREIRE, Paulo. Pedagogia da autonomia: Saberes necessários à prática educativa. São Paulo: Paz e Terra, 1996.

11. Pedagogia do Oprimido. 17a . ed. Rio de Janeiro: Paz e Terra, 1987.

12. FRIEDLANDER, M. R. Alunos-monitores: uma experiência em Fundamentos de Enfermagem. Revista Esc. Enf. USP, 18(2): p.113, 1984.

13. NATÁRIO,E.G.;SANTOS,A.A.A. Programa demonitores para o ensino superior. Estudos de Psicologia, Campinas, v. 27 (3), p. 355-364, 2010. Disponível em: <http://dx.doi.org/10.1590/S0103166X2010000300007>. Acesso em: 15 de mai. 2017.

14. SANTOS, M.M.; LINS, N.M (Orgs.). A monitoria como espaço de iniciação à docência: possibilidades e trajetórias. Natal, RN: EDUFRN - Editora da UFRN, 2007.

15. SIQUEIRA, R.R.; VARGAS, M.A.M.; SOARES, M.J.N. Adolescentes e o consumo sustentável percepções e estilos de vida. 1.ed. Aracaju: IFS, 2016.

16. TARDIF, M. Saberes docentes e formação profissional. 16. ed. Petrópolis: Vozes, 2014. 